\title{
Sujeitos-Wh e movimento para posições focais em sentenças infinitivas do português brasileiro
}

\author{
Wh-subjects and movement for focal positions \\ in Brazilian Portuguese infinitive sentences
}

Paulo Medeiros Junior

Universidade de Brasília, Brasília, DF / Brasil

medeirosjunior33@gmail.com

Resumo: Este trabalho põe em discussão a derivação de sentenças infinitivas que complementam verbos como 'ver' e 'ouvir' e que apresentam um sujeito-Wh. Como se vê na empiria, apenas as sentenças com um 'stress' focal no sintagma-Wh sujeito constituem uma derivação convergente. Argumenta-se que o que aparentemente se configura numa construção com Wh in situ é na verdade uma construção com movimento curto do Wh para o Spec-FocP na projeção focal interna da sentença matriz (assumindo a ideia de BELLETTI, 2004), e que, em português, o traço-Wh de sintagmas-Wh é valorado sincreticamente com o traço de foco em projeções focais, como propõe Kato (2004). Essa proposta ainda prevê que sentenças infinitivas são defectivas também quanto à projeção de uma periferia interna, fato que explica certa assimetria verificada nos dados.

Palavras-chave: sujeitos-Wh; infinitivas; traços de foco.

Abstract: This paper concerns the derivation of non-finite sentences that complement verbs of the type of 'see' and 'hear' and contain a Whsubject. Analyzed data evidence that sentences that carry a Wh-phrase with a stressed Wh-subject are convergent, contrary to sentences that do not. We argue that the apparent Wh in situ construction is in fact a sentence where some instance of Wh-movement takes place. The idea is 
that the Wh-phrase is moved to the Spec-FocP in the low IP area (in the terms of BELLETTI, 2004) and that in Portuguese the Wh feature of Whphrases is checked with a Focus feature in focus projections, according to Kato (2004). This proposal still states that sentences of an infinitival nature are defective also in terms of projecting an internal periphery, what seems to explain certain asymmetry facts observed in data.

Keywords: Wh-subjects; non-finite clauses; focus features.

Recebido em 19 de outubro de 2017 Aceito em 16 de fevereiro de 2018

\section{Introdução}

A discussão sobre a natureza das operações que envolvem a derivação de sentenças com sujeitos-Wh é vasta. A noção geral é que, em contraste com as interrogativas com Wh objeto, interrogativas de sujeito são claramente ambíguas quanto ao movimento do constituinteWh em sintaxe aberta. A ordem linear de dados como (1) pode facilmente viabilizar a análise de uma derivação com ou sem movimento de Spec-T para Spec-C.

(1) Quem espirrou? $\rightarrow\left[{ }_{\mathrm{CP}}\right.$ Quem $\left[{ }_{\mathrm{TP}}\right.$ quem espirrou $\left.]\right] /{ }_{\mathrm{CP}}\left[{ }_{\mathrm{TP}}\right.$ Quem espirrou $\left.]\right]$

A possibilidade de interpretação da derivação sem movimento nesses casos ficou conhecida como a Hipótese do Movimento Vácuo (cf. GEORGE, 1980; CHOMSKY, 1986), segundo a qual um sujeito-Wh não se move localmente para Spec-CP.

A análise proposta para o inglês baseia-se em evidências empíricas como as seguintes:

1) O movimento de Whs-complemento é claramente percebido na sentença;

2) Construções com interrogativas de wh-não-sujeito apresentam inversão do auxiliar, fato que não é observado em interrogativas com Wh-sujeito.

É isso que se pode ver nos dados em (2) e (3) a seguir: 
(2) $\left[_{\mathrm{CP}} \mathrm{Who}_{\mathrm{k}}\right.$ have ${ }_{\mathrm{i}}\left[_{\mathrm{TP}}\right.$ they $t_{\mathrm{i}}$ seen $\left.\left.t_{\mathrm{k}}\right]\right]$ ?

(3) $\left[_{\mathbf{C P}}\left[{ }_{\mathbf{T P}}\right.\right.$ Who painted the room $\left.]\right]$ ?

Se a discussão gira em torno de interrogativa raiz ou mesmo de interrogativas encaixadas de natureza finita, não é impossível assumir para o português uma hipótese como a do movimento vácuo de George, aplicável aos dados em (4):

(4) a. $\left[{ }_{\mathrm{CP}}\left[{ }_{\mathrm{TP}}\right.\right.$ Quem chorou $\left.]\right]$ ?

b. O João quer saber $\left[{ }_{C P}[\right.$ TP quem chorou $\left.]\right]$.

Talvez, se pudesse argumentar, de início, seguindo Chomsky (1995), que - em essencial - traços são movidos em uma operação de checagem. O pied-piping de toda uma categoria só ocorre nos casos em que o movimento é essencial para convergência; caso contrário, questões de economia o bloqueiam.

Entretanto, se postos em discussão, os dados em (5) e (6) com Wh-sujeito em sentenças infinitivas que complementam verbos como ver e ouvir parecem trazer alguma dificuldade a um tratamento do fenômeno em termos de movimento de traços.

Sejam os dados:

(5) a. *O João viu quem espirrar.

b. O João viu QUEM $\uparrow \downarrow$ espirrar? ${ }^{1}$

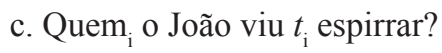

(6) a. *A Maria ouviu quem chorar.

b. A Maria ouviu QUEM $\uparrow \downarrow$ chorar?

c. Quem ${ }_{\mathrm{i}}$ a Maria ouviu $t_{\mathrm{i}}$ chorar?

\footnotetext{
${ }^{1}$ Os símbolos $\uparrow \downarrow$ indicam a entonação das sentenças: ascendente no caso de uma pergunta eco; descendente, no caso de uma interrogativa comum. Assim, está-se assumindo aqui a dupla possibilidade de interpretação de sentenças como 5 e $6 \mathrm{~b}$, a saber, a possibilidade de interpretá-las como pergunta eco ou como uma requisição original por informação (pergunta comum).
} 
Sentenças como as que aparecem em (c) mostram claramente o deslocamento do elemento-Wh da posição de sujeito $^{2}$ da subordinada para a sentença matriz. Além disso, com o Wh in situ, só as sentenças em que esse elemento recebe uma entonação focal (ascendente ou descendente) são aceitáveis. ${ }^{3,4} \mathrm{O}$ que os dados parecem mostrar é uma interação entre as questões de valoração do traço-Wh e das propriedades dos complementos do tipo de verbo da matriz; é preciso, portanto, que se avaliem questões relacionadas a um e outro fenômeno, se há a intenção de explicar o paradigma em (5) e (6).

Um dos pontos básicos na análise de dados com verbos de percepção tem sido o de determinar a estrutura de construções infinitivas que eventualmente os complementam, constituindo o que se convencionou chamar "complementos de percepção direta", como as sentenças em (5) e (6) b (cf. FELSER, 1999; RODRIGUES, 2006).

${ }^{2}$ Quanto ao que se entende aqui por posição de sujeito, entenda-se inicialmente posição temática. $\mathrm{O}$ decorrer da argumentação procurará evidenciar que nesses casos o Wh sofre movimento cíclico da posição temática para a posição de Spec-T e em seguida para a posição mais alta na estrutura.

${ }^{3}$ Obviamente, a discussão sobre o movimento de Whs sujeito se dá em termos de movimento local para Spec-CP. Em todo caso, em dados como (5) e (6) c observa-se claramente a aplicação de movimento sobre o Wh, considerando o fato de que esse elemento precisa nascer na subordinada, mas encontra-se deslocado, em sua posição final, na periferia da matriz. A pergunta é: nos dados em (5) e (6) b ocorre movimento? A isso procuramos responder no desenrolar da discussão.

${ }^{4}$ Construções com o verbo flexionado na encaixada apresentam um paradigma distinto. Observe-se que em (i) não é necessária qualquer entonação focal sobre o sintagma-Wh para salvar a gramaticalidade das sentenças. Segue-se disso que sentenças como as que aparecem em (ii) têm sua agramaticalidade explicada por uma ausência do traço-Wh no $\mathrm{C}$ da matriz (considere-se a força - interrogativa da sentença), não podendo haver qualquer operação de valoração de traços entre o $\mathrm{C}$ mais alto e a categoria-Wh. Além disso, entende-se que nesses casos esse traço seja valorado já na posição encaixada.

(i) a. O João perguntou quem chorou.

b. A Maria quer saber quem gritou.

(ii) a. *Quem o João perguntou $t$ chorou.

b. ${ }^{*}$ Quem a Maria quer saber $t$ gritou. 
Trabalhos como os de Rouveret e Vergnaud (1980), Koster e May $(1982)^{5}$ e Kayne (1984) optam por uma análise em termos de uma estrutura contendo um CP, enquanto Emonds (1976), Borer (1986) e Radford (1997) entendem que as orações infinitivas em questão se constituem em TPs.

Felser (1999) argumenta que a agramaticalidade de sentenças como (7) inviabiliza uma análise em termos do CP e que instâncias de comportamento sintático distinto entre complementos infinitivos de verbos de percepção e as infinitivas em geral também desautorizam uma análise em termos do TP para essas construções.

(7) a. *Mary couldn't see $\left[{ }_{\mathrm{CP}}\right.$ what $\left[\mathrm{C}^{\prime}\right.$ John drawing $\left.]\right]$.

b. *Mary couldn't hear $\left[{ }_{\mathrm{CP}}\right.$ which song $\left[_{\mathrm{C}^{\prime}}\right.$ John sang]].

(FELSER, 1999, p. 91)

Trata-se, portanto, de uma discussão nada consensual. Movimento de um sujeito-Wh e a constituição estrutural dos complementos infinitivos de verbos de percepção são, nesse panorama, questões cruciais a serem debatidas.

Assim, com base na observação dos dados em (5) e (6), chega-se a algumas questões que precisam ser postas em discussão. A primeira e principal delas é a avaliação das condições de derivação das referidas construções e, consequentemente, a necessidade de explicar o que viabiliza as sentenças em (5) e (6)b e bloqueia as sentenças em (5) e (6) a. Essa questão passa necessariamente pela discussão do tipo de estrutura que apresentam os complementos infinitivos dos verbos ver e ouvir nas referidas construções. Procuro mostrar aqui que não há como sustentar, em face dos dados, uma análise com movimento vácuo de sujeito para os dados do português do Brasil. ${ }^{6} \mathrm{~A}$ ideia básica que procurarei constituir aqui é a de que sujeitos-Wh nesse tipo de sentenças precisam mover-se em sintaxe aberta de Spec- $v$ para Spec-T (na sentença encaixada) e novamente, em sintaxe aberta, para o domínio do v na matriz, por questões de Caso,

\footnotetext{
${ }^{5}$ Hipótese do Paralelismo Estrutural: a estrutura é uniforme entres tipos de sentenças; assim complementos infinitivos de verbos de percepção são estruturalmente análogos a sentenças completas.

${ }^{6}$ Ponho de lado aqui a questão do movimento local e passo a discutir movimento de sujeitos-Wh de forma generalizada.
} 
e para checar um traço-Wh, conjuntamente com um traço de Foco. ${ }^{7}$ É sobre essas questões que o presente trabalho se debruça. Para a análise do fenômeno, vou adotar aqui, a versão de Fase do Programa Minimalista da teoria de Princípios e Parâmetros (cf. CHOMSKY, 2000, 2001, 2005).

$\mathrm{O}$ artigo se estrutura da maneira como segue: na seção 2, ocupome da avaliação das propostas de análise para a estrutura de infinitivas que complementam verbos de percepção, na intenção de determinar qual proposta se adéqua melhor aos dados do português. A seção 3 traz uma discussão sobre movimento-Wh e o problema dos traços, na qual se avaliam questões como para onde e por que Whs se movem em perguntas. Na seção 4, avalio a questão do movimento para posições focais, assumindo a hipótese de Karimi (2003), segundo a qual movimento para Foco é ativado por checagem de um traço [-interpretável]. Ainda nessa seção, discuto o problema da atribuição de Caso aos Whs sujeitos de infinitivas e delineio a proposta final deste trabalho. A seção 5 traz as considerações finais e as questões em aberto para futuras investigações.

\section{Complementos de verbos de percepção direta: avaliando as hipóteses de análise da sentença infinitiva}

A questão elementar que se põe quanto aos dados em (5) e (6) é a seguinte: o que faz com que as sentenças em (a) sejam agramaticais em oposição às que se encontram em (b) e (c)? O problema pode estar relacionado à verificação do traço-Wh em sentenças desse tipo, questão que pode ter ligação direta com o tipo de estrutura que se supõe apresentar a sentença infinitiva iniciada pelo sintagma-Wh.

E importante, portanto, que se avaliem as propostas estruturais apresentadas na introdução, para que se possa procurar determinar o tipo de estrutura que essas sentenças infinitivas apresentam e avaliar a maneira como são derivadas.

\subsection{A hipótese do CP}

Estruturas como as que se põem em análise já foram avaliadas como constituintes sentenciais de categoria CP (cf. ROUVERET; VERGNAUD, 1980; REULAND, 1981; KAYNE, 1984), conforme mencionado na introdução. Isso se emparelha com a Hipótese do

\footnotetext{
${ }^{7}$ Agradeço a Mary Kato (comunicação pessoal) por me sugerir essa ideia.
} 
Paralelismo Estrutural de Koster e May (1982), que propõe uma isonomia estrutural para as sentenças, mesmo de tipos diferentes. Essa questão é, no entanto, problemática.

Como observa Felser (1999), a ausência obrigatória de complementizadores realizados e marcadores de finitude nessas construções traz alguma complicação para a análise do CP. A argumentação é que as propostas para esse tipo de análise têm de assumir ou que $\mathrm{C}$ e I/T estejam presentes estruturalmente, mas sem conteúdo, ou que essas projeções contêm núcleos fonologicamente nulos, que estão associados a um conjunto de traços formais ou semânticos. (FELSER, 1999, p. 91).

O problema com a primeira hipótese é que o princípio de Interpretação Plena (FI, cf. CHOMSKY, 1995) inviabiliza tal abordagem: uma projeção sintática sem conteúdo semântico não pode ser interpretada na interface semântica. Assim sendo, sobra a segunda hipótese: a da existência de núcleos $\mathrm{C}$ e I fonologicamente nulos.

Um problema para a segunda análise, apontado em Felser (1999), é o fato de que, como esses núcleos nunca apresentam nenhum tipo de material lexical, fica difícil determinar qual o tipo de traço que carregam. Além disso, supõe-se que $\mathrm{C}$ indique o tipo oracional (cf. CHENG, 1991) e seja o lugar onde se codifica o modo e a força ilocucionária da sentença (CHOMKY, 1995); um C nulo numa sentença plena representaria problemas para a codificação de sua força.

Uma questão relevante aventada em Felser (1999) - que parece contrariar a hipótese do $\mathrm{CP}$ - assume particular interesse para nossa argumentação aqui. Ela diz respeito ao fato de não se observar qualquer instanciação de movimento-Wh curto em infinitivas, o que se dá a ver em (9), contrariamente ao que acontece em sentenças finitas como (8):

(8) O João viu $\left[\left[_{\mathrm{CP}}\right.\right.$ quem $\left[\left[_{\mathrm{TP}}\right.\right.$ a Maria beijou $\left.\left.t_{\mathrm{i}}\right]\right]$
(9) *O João viu $\left[\left[_{\mathrm{CP}}\right.\right.$ quem $\left[\left[_{\mathrm{TP}} \text { a Maria beijar } t_{\mathrm{i}}\right]\right]^{8}$

${ }^{8}$ Uma questão interessante nesse ponto é o fato de que, em sentenças finitas que complementem um verbo do tipo de ver (como em (8)), o Wh precisa necessariamente aparecer na posição intermediária. Uma construção com esse elemento in situ não é aceitável, como se vê em (i), assim como seu posicionamento na periferia da matriz, tal como em (2):

(i) *O João viu a Maria beijou quem/QUEM?

(ii) *Quem o João viu a Maria beijou? 
Considerando o fato de que o movimento curto do sintagma-Wh pode ocorrer livremente com complementos finitos como em (8), que se assume apresentar a projeção da camada $\mathrm{CP}$, mas é bloqueado em infinitivas como (9), pode-se concluir que as sentenças postas em análise aqui não devem de fato projetar o sistema $\mathrm{C}$.

Outro argumento desfavorável à hipótese do $\mathrm{CP}$ baseia-se no fato de que em interrogativas observa-se um fenômeno que ficou conhecido em fases anteriores do programa como o duplo preenchimento do Comp, com a realização do núcleo C e a presença de um sintagma-Wh em Spec$\mathrm{CP},{ }^{9}$ como se pode ver em (10) e (11) a seguir:

(10) a. $\left[{ }_{\mathrm{CP}}\right.$ Quem ${ }_{\mathrm{i}}\left[{ }_{\mathrm{C}}\right.$ que $\left[{ }_{\mathrm{TP}} t_{\mathrm{i}}\right.$ viu o João]]]?

b. Quero saber $\left[{ }_{\mathrm{CP}}\right.$ quando ${ }_{\mathrm{i}}\left[_{\mathrm{C}}\right.$ que $\left[{ }_{\mathrm{TP}}\right.$ ele chegou $\left.\left.\left.t_{\mathrm{i}}\right]\right]\right]$.

(11) a. $\left[_{\mathrm{CP}}\right.$ Quem ${ }_{\mathrm{i}}\left[_{\mathrm{C}}\right.$ que $\left[_{\mathrm{TP}}\right.$ o João viu $t_{\mathrm{i}}$ chegar $\left.\left.]\right]\right]$ ?

Quando a Numeração de uma interrogativa (seja ela raiz ou encaixada) contém um item que, que realiza fonologicamente o $\mathrm{C}$, o pied-piping de todos os traços do constituinte-Wh passa a ser obrigatório. A permanência do Wh in situ resulta na agramaticalidade da sentença. ${ }^{10}$ É o que se pode observar em (12d) e (13d), logo abaixo:

O problema em (ii) é facilmente explicado pelo fato de o $\mathrm{CP}$ da matriz não conter um traço [+Wh], considerando que se trata de uma declarativa comum. (i) é ruim com ou sem a entonação focal no Wh. Isso pode estar relacionado com a natureza da percepção num e noutro: em (8), a percepção é de uma entidade: o que João viu foi a pessoa que Maria beijou; contrariamente, em (9), a percepção é a de um evento: o que João viu foi o evento, o acontecimento de Maria beijar alguém. No primeiro caso (8), o operador tem uma natureza definida, há aí um traço de definitude (pode-se o substituir pela perífrase aquele/aqueles que). No caso de (9), a natureza do operador é totalmente indefinida: é a identidade do beijado que se interroga.

${ }^{9}$ Fato já descrito em trabalhos como Lobato (1986), Mioto (1994) e Medeiros Junior (2005).

${ }^{10}$ Pode-se sugerir que o item lexical que em C seja a realização morfológica do traço [+Wh]. A realização morfo-fonológica desse traço evidenciaria uma visão forte do Critério-Wh de Rizzi (1991). Uma alternativa pode ser entender essa questão nos termos do que propõe Watanabe (2006), que se trata de um traço pied-piper, que exige a presença de material fonológico em Spec-CP. 
(12) a. O João viu quem?

b. Quem o João viu?

c. Quem que o João viu?

d. *que o João viu quem?

(13) a. Quem o João viu espirrar?

b. O João viu QUEM espirrar?

c. Quem que o João viu espirrar?

d. *que o João viu QUEM espirrar?

Observe-se que em sentenças como (13b), não é possível inserir o item que. Esse procedimento torna a sentença agramatical:

(14) *O João viu QUEM que chegar?

Essa pode ser considerada mais uma evidência de que não há de fato uma camada CP na constituição estrutural desse tipo de infinitiva, o que conduz à avaliação de outras propostas estruturas para tais construções. ${ }^{11}$ Nas subseções a seguir, avalio outras propostas de análise estrutural dadas a esse tipo de sentença.

\subsection{Uma análise em termos do VP}

Felser (1999) sugere inicialmente que complementos infinitivos de percepção direta poderiam ser analisados como VPs nus. A derivação de uma estrutura como a que aparece em (15) se daria da forma como se vê em (16):

${ }^{11}$ Um problema potencial para a análise que faço aqui da agramaticalidade de (15) pode ser delineado como segue. No caso de se querer sustentar uma análise do CP, pode-se tentar explicar a agramaticalidade de sentenças como (15) com base em uma incompatibilidade entre as propriedades selecionais de verbos de percepção direta como ver e o $\mathrm{C}$ que ele toma como complemento. Verbos desse tipo selecionam um C[-finito]; a presença do complementador caracteriza o $\mathrm{C}$ como [+finito] automaticamente: essa seria a explicação para a má formação da sentença. Ou, poder-se-ia avaliar essa questão como uma incompatibilidade entre os traços de $\mathrm{C}$ e $\mathrm{T}$. Um complementador exige um $\mathrm{T}$ finito e temos aqui uma sentença infinitiva. 
(15) We saw John draw a circle.

(16) We saw $\left[{ }_{v \mathbf{P}} \operatorname{John}_{\mathrm{i}}\left[{ }_{v^{\prime}} \ldots t_{\text {see }} \ldots\left[_{v \mathbf{P}} t_{\mathrm{i}}\left[{ }_{v^{\prime}} \operatorname{draw}\left[_{v \mathbf{P}} t_{\text {draw }}\left[{ }_{V \mathbf{P}} t_{\text {draw }}\left[{ }_{D P}\right.\right.\right.\right.\right.\right.\right.$ a circle $\left.\left.\left.\left.\left.\left.]\right]\right]\right]\right]\right]\right]$.

A autora, entretanto, argumenta - com base na apreciação de construções com there - que uma análise em termos de um VP nu também enfrenta alguns problemas. Seja a sentença em (17):

(17) We wouldn't like to see [there arrive any problems from this]

(FELSER, 1999, p. 101)

A ideia é que posições argumentais dentro do sintagma verbal devem ser ocupadas por expressões $\theta$-marcadas; a geração de there (um expletivo puro) no especificador de VP ou mesmo $v \mathrm{P}$ não seria uma possibilidade viável.

Nessas circunstâncias, caso se assuma a hipótese de que inacusativos não apresentam a projeção $v \mathrm{P}$, é preciso considerar que o expletivo em (18) deve estar ocupando o especificador de outro núcleo funcional acima de VP:

(18) ... see $\left[{ }_{\gamma \mathbf{P}}\right.$ there $\left[\left[_{\mathbf{V P}}\left[{ }_{\mathbf{V}}\right.\right.\right.$, arise $\left[{ }_{D P}\right.$ any problems $\left.\left.\left.]\right]\right]\right]$

Com base nessa argumentação, Felser propõe uma análise das infinitivas em questão como sendo Sintagmas Aspectuais. Para ela, a única configuração adequadamente capaz de descrever o que acontece em complementos infinitivos de verbos de percepção é a que se mostra em (19) a seguir, em que o $v$ P infinitivo é selecionado por um núcleo Asp:

(19) $\left[_{\mathrm{CP}}\left[{ }_{v \mathrm{P}}\left[\left[_{\mathrm{VP}}\left[{ }_{\mathrm{AspP}}\left[{ }_{\nu \mathrm{P}}[\mathrm{VP}]\right]\right]\right]\right]\right]\right.$.

A ideia original de Felser é que os verbos se movam para Asp e a posição de Spec-AspP sirva de local de pouso intermediário para o sujeito da infinitiva, em seu caminho até o Spec do $v \mathrm{P}$ na matriz onde valora o traço de Caso. ${ }^{12}$ Nessa posição, segundo essa proposta, seriam gerados os expletivos puros em sentenças como (18).

\footnotetext{
${ }^{12}$ Embora desde Pollock (1989) assuma-se que o alcance do verbo em inglês é mais baixo do que em francês, na análise de Felser, ele sai do domínio lexical e é alçado ao domínio de Asp para que, (como já dito anteriormente) ativando a projeção aspectual, o Spec da projeção sirva de local de pouso para o sujeito em seu caminho para uma
} 
A hipótese de AspP pode ser útil para avaliar questões referentes a partículas verbais como (-ing) do inglês [como em I saw John draw(ing) a circle] ou (-ndo) do português, na constituição de gerundivas [Eu vi o João anda(ndo) na rua]. Trata-se, portanto, de uma alternativa viável de análise, considerando a argumentação da seção anterior de que a hipótese do CP deve ser descartada. Essa análise, entretanto, não se mostra tão adequada para a análise dos dados do português, considerando a existência nessa língua de flexão do infinitivo. A seguir, avalio a questão do TP e proponho ser esta a opção mais viável de análise, considerando o fato de infinitivos do português apresentarem a possibilidade de aparecerem flexionados.

\subsection{A hipótese do TP}

Trabalhos como o de Emonds (1976) propunham que orações infinitivas complementos de verbos de percepção seriam derivadas de infinitivas plenas com o apagamento obrigatório da partícula to; essas construções deveriam, portanto, ser interpretadas como elementos sintáticos de natureza I (TPs em termos minimalistas). Trabalhos como os de Borer (1986) propõem alternativamente que esse tipo de sentença seja encabeçado por um Infl de natureza degenerada, o que justificaria o contraste entre o tipo de comportamento de sentenças plenas (com a partícula to) ou defeituosas (sem o to).

Felser (1999) mostra-se contrária a esse tipo de análise. Para ela, não há evidências suficientes para afirmar que complementos de verbos de percepção direta derivem de infinitivas comuns com o apagamento de to ou mesmo que contenham um núcleo temporal não finito foneticamente não realizado. Um dos argumentos que a autora utiliza para defender sua hipótese é o de que há claras distinções semânticas entre as infinitivas encabeçadas por to e as infinitivas complementos de verbos de percepção direta.

Recentemente Hornstein, Martins e Nunes (2008) argumentam que complementos infinitivos de verbos de percepção apresentam duas possibilidades de estrutura: podem ser CPs ou TPs, fato que é definido

posição de caso. O que Felser propõe (1999, p. 123) é que considerando que ocorra o alçamento do DP objeto para uma posição mais alta um segundo Spec em vP) e do DP sujeito para o domínio do $v$ na matriz, supõe-se que o verbo tem necessariamente de ter se deslocado para a projeção aspectual. Mesmo assim, há uma diferença (entre inglês e francês) no alcance do verbo; em inglês ele permanece mais baixo que em francês. 
pelo tipo de predicado que os integra ( $\mathrm{CP}$ no caso de conterem um predicado proposicional/epistêmico e TP, no caso de apresentarem um predicado eventivo). As sentenças em (20) e (21) a seguir exemplificam cada um dos casos discutidos pelos autores:

(20) John saw them hit Fred

(21) John was seen to know French

(HORNSTEIN; MARTINS; NUNES, 2008, p. 198-200)

Segundo esses autores, a atribuição de Caso ao nominal sujeito do infinitivo em casos como (21) acontece com base em duas operações distintas, ${ }^{13}$ devidas ao fato de que tanto o infinitivo, quanto o nominal sujeito, encontram-se equidistantes do núcleo do verbo leve da matriz, o qual atribui Caso excepcional ao NP: ${ }^{14}$

1. Ocorre uma primeira operação de checagem com o infinitivo (que se comporta como um nominal); e

2. Ocorre uma segunda operação de checagem com o DP sujeito.

Os dados que por ora analisamos apresentam sentenças infinitivas do tipo de (21), constituídas por predicados eventivos; encaixam-se, portanto, na análise de tais estruturas como TPs.

Uma análise em termos do TP para o português parece mesmo mais adequada, apesar da consistente argumentação de Felser em favor do VP, (delineada em 2.1), por se considerar a possibilidade da ocorrência de flexão (de pessoa e número) em infinitivos do português, ${ }^{15}$ contrariamente

\footnotetext{
${ }^{13} \mathrm{O}$ panorama dessa abordagem é o da checagem de traços.

${ }^{14}$ A argumentação final é que Inglês e Português Europeu comportam-se da mesma maneira quanto ao fenômeno, apesar da evidente diferença entre as línguas, considerando o caso de a segunda apresentar infinitivos flexionados.

${ }^{15}$ Conforme apontado a mim por Juanito Avelar (c.p.), uma alternativa seria assumir que o núcleo ASP portasse os traços- $\varphi$ necessários para uma operação Agree com infinitivos flexionados. Uma projeção ASP, entretanto, não resolve os problemas que os dados do presente trabalho levantam quanto à necessidade de se focalizar o Wh in situ para que a sentença seja aceitável. Necessita-se, portanto de uma projeção focal para que se valore o traço de foco. A esse respeito, cf. seções 3.1 e 4.2.
} 
ao que acontece na língua inglesa. ${ }^{16}$ No presente trabalho, não precisarei lançar mão dos detalhes menores da proposta de Hornstein, Martins e Nunes (2008), mas passo a assumir que ela seja a mais adequada para o tratamento dos dados da língua, ao se levar em consideração a flexão do infinitivo. ${ }^{17}$ A seguir, encaminho-me à segunda parte da argumentação, a saber, a análise das construções com Wh focalizado (apresentadas na introdução), com o intuito de explicar por que (5a) e (6a) são agramaticais em contraste com (5b) e (6b) e como as sentenças em b se relacionam com as que aparecem em c.

\section{Movimento-wh e a questão dos traços}

Tendo avaliado a estrutura de complementos sentenciais em construções de percepção direta como TPs, passo agora à análise dos dados postos em (5) e (6), tentando explicar a assimetria apresentada entre as sentenças em (a) e (b).

\subsection{Por que Whs se movem?}

Em Cheng (1991), toda instância de movimento-Wh é interpretada como um procedimento que resulta na tipificação sentencial. O deslocamento de um sintagma-Wh para a periferia da sentença serve para tipificá-la como interrogativa.

Segundo Cheng (1991), línguas que não dispõem de movimento sintático de sintagmas-Wh apresentam outra estratégia para tipificar

\footnotetext{
${ }^{16}$ Observe-se que Horntein, Martins e Nunes (2008) estendem essa proposta para o inglês (mesmo apesar das diferenças evidentes entre as duas línguas quanto à flexão do sujeito), por entenderem que se trata de um comportamento uniforme dos infinitivos nesse contexto sintático.

${ }^{17}$ Não há, na argumentação de Hornstein, Martins e Nunes (2008), a proposição de qualquer distinção estrutural de sua proposta em relação a hipóteses do VP como a defendida por Felser (1999) (conforme apontado por um dos revisores deste paper); toda a argumentação desses autores centra-se nas propriedades do português (por apresentar flexão no infinitivo) e na necessidade de se obter uma explicação que dê conta das peculiaridades desse tipo de dado. Como mencionado acima, assumo a hipótese em questão em razão das mesmas questões, mesmo entendendo que uma derivação com a projeção de Asp poderia resolver algumas das questões. A discussão da nota 15 acima, de certo modo, pontua essas questões.
} 
uma sentença como interrogativa; por exemplo, o uso de partículas interrogativas. De acordo com essa visão, as línguas se distinguiriam parametricamente quanto a apresentar movimento-Wh ou partículas interrogativas.

Desde Chomsky (1995), propõe-se que aplicações de movimento são sempre condições de último recurso, que decorrem da presença de traços não-interpretáveis. Em termos gerais, traços formais que não sejam interpretáveis em LF precisam ser verificados e eliminados no decurso da derivação a fim de que se garantam condições de interpretabilidade na interface.

Supõe-se que uma relação de checagem (nessa fase do programa a visão é a de checagem) ocorra entre um núcleo funcional que carrega determinado traço (em geral [-interpretável]) e um item lexical compatível em termos de traços; supõe-se que o mesmo traço no item lexical seja +interpretável, à exceção do traço de Caso.

Numa relação de checagem, uma operação denominada Attract atrai para o domínio de checagem de um núcleo $\mathrm{X}^{0}$ apenas os traços necessários para a checagem; se o mínimo que Attract conseguir carregar for toda a categoria, temos a aplicação de movimento em sintaxe aberta. Isso deve, no entanto, por razões de economia, ser evitado ao máximo: sempre que possível, apenas os traços devem ser movidos.

Considerando que o mínimo necessário para convergência em PF seja o deslocamento de toda uma categoria, o movimento deve ser permitido. Uma vez no domínio de checagem de $\mathrm{X}, \alpha$ verifica o traço [-interpretável] do núcleo e o elimina, embora o mesmo traço em $\alpha$, sendo [+interpretável], ainda permaneça visível para a aplicação de outras instâncias de checagem de mesma natureza. Segundo Chomsky, uma categoria $\alpha$ pode ser concatenada ou alçada ao domínio de checagem de um determinado núcleo; no caso da elevação, a categoria pode ser movida à posição de Spec do núcleo ou pode sofrer adjunção. (CHOMSKY, 1995, p. 395 $)^{18}$ Chomsky considera que o traço-Wh seja [+interpretável]

\footnotetext{
${ }^{18}$ Em Chomsky (2000) e trabalhos subsequentes, a arquitetura das operações formais implicadas na constituição da linguagem sofre uma reformulação substancial. Nesse trabalho inicial lança-se o programa de Fases, cujas bases vêm sendo exploradas em muitas investigações até hoje. Na seção 3.3, apresenta-se uma discussão que avalia essa nova "fase" do programa e que é a perspectiva adotada nesse trabalho. A visão de fases anteriores do programa pode ser interessante para avaliar pontos específicos em momentos específicos.
} 
em sintagmas-Wh e [-interpretável] nos núcleos $\mathrm{C}$ de interrogativas. Parametricamente, as línguas se distinguem por terem esse traço forte ou não (o que determina sua verificação antes ou depois do ponto conhecido como Spell-Out, em que todos os traços fonológicos são retirados e mandados para a fonologia). Línguas como o inglês exemplificam o primeiro caso; elas têm o traço-Wh forte e apresentam inevitavelmente movimento visível do sintagma-Wh. Línguas do tipo do chinês ilustram o segundo caso, o das que possuem um traço-Wh fraco e nunca apresentam movimento aparente de palavras-Wh.

\subsection{Para onde Whs se movem?}

Convencionalmente se supõe que Whs em sentenças interrogativas comuns encontrem-se em Spec-CP, de onde operam sobre toda a sentença, caracterizando-a como interrogativa típica (cf. CHENG, 1991). É nessa posição que se encontram em configuração propícia à checagem com um núcleo $\mathrm{C}^{0}$ que contém um traço [-Wh], já que o c-comanda (cf. CHOMSKY, 1995).

Desde Rizzi (1997), tem-se interpretado o CP como um sistema complexo cuja funcionalidade se presta à resolução de questões a priori discursivas. Para Rizzi (1997), o CP se constitui de uma série de posições funcionais para as quais sintagmas podem ser movidos, principalmente devido a questões de fundo discursivo. O CP cindido de Rizzi (1997) tem a seguinte configuração:

(22) ForceP $\left[\right.$ Force $^{0}\left[\right.$ TopP $\left[\right.$ Top $^{0}\left[\right.$ FocP $\left[\right.$ Foc $^{0}\left[\right.$ TopP $\left[\right.$ Top $^{0}\left[\right.$ FinP $\left[\right.$ Fin $^{0}$ [IP]]]]]]]]] $]^{19}$

${ }^{19}$ Obviamente, para além das questões de ordem discursiva, há questões de ordem sintática e até mesmo morfológica para a proposição da cisão do sistema CP. Parte da argumentação de Rizzi, por exemplo (1997, p. 283), tem a ver com as questões relativas à complementação (que tocam a parte mais alta da sentença) e às questões voltadas à finitude (que tocam a interface de $\mathrm{C}$ com $\mathrm{T}$ ), razões sintáticas no que tange à existência de tópicos e à distribuição de sujeitos pós-verbais, bem como a interação dessas estruturas com a ocorrência de expressões focalizadas (RIZZI, 1997, p. 287). Mais debates sobre essa questão podem ser vistos em Guesser e Quarezemin (2013) e Quarezemin (2009). 
Segundo Rizzi (1997), na língua inglesa, o Spec-FocP hospeda sintagmas-Wh em interrogativas matrizes, após a incorporação de I em Foc.

Nas perguntas encaixadas, entretanto, o pronome interrogativo não pode seguir o constituinte marcado com Foco; nesses casos o traço [+Wh] é selecionado diretamente pelo predicador da matriz e precisa estar adjacente a ele:

(23) *I wonder Tom, why anyone would want to meet.

Assim, entende o autor que em interrogativas encaixadas do inglês o sintagma-Wh não pode estar focalizado.

Postos em avaliação, os dados do português parecem demonstrar um comportamento um tanto diferente. Observe-se que uma interrogativa encaixada comum como (24) pode ser parafraseada da maneira como se vê em (25):

(24) A Maria quer saber [quem pegou o dinheiro do cofre].

(25) A Maria quer saber [quem foi que pegou o dinheiro do cofre].

Como se pode observar, é possível clivar o constituinte-Wh em interrogativas indiretas do português, exatamente como o que ocorre em interrogativas matrizes nessa língua:

(26) a. Quem você viu no parque?

b. Quem foi que você viu no parque?

Assim, é apropriado entender que, tal como ocorre em italiano (cf. RIZZI, 1997; BIANCHI, 1999), em interrogativas indiretas do português, o traço $\left[+\mathrm{Wh}\right.$ ] é realizado em $\mathrm{I}^{0}$, que se move para Foc, exatamente como nas matrizes, e o sintagma-Wh pode ter seu traço checado em Spec-FocP.

Retomemos aqui o paradigma posto em (5) e (6), reproduzido a seguir como A e B:

(A) a. *O João viu quem espirrar.

b. O João viu QUEM $\uparrow \downarrow$ espirrar?

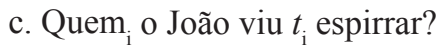


(B) a. *A Maria ouviu quem chorar.

b. A Maria ouviu QUEM $\uparrow \downarrow$ chorar?

c. Quem ${ }_{\mathrm{i}}$ Maria ouviu $t_{\mathrm{i}}$ chorar?

Observando com cuidado os dados em (A) e (B), percebe-se, em ambos os casos, que o sintagma-Wh porta um traço de Foco. Em b, a entonação focal salva a sentença da agramaticalidade (vista em a); em c, entende-se, com Rizzi, que o sintagma-Wh esteja em Spec-FocP e, passo a propor daqui em diante (seguindo KATO, 2004) ${ }^{20},{ }^{21}$ que o traço-Wh seja checado sincreticamente nessa posição.

Se o que se propõe acima estiver correto, começamos a delinear aqui uma provável explicação para o paradigma que se encontra nos dados em (5) e (6), em que só se obtém sentenças bem-formadas quando o sintagma-Wh que as integra apresenta uma entonação focal.

Antes, todavia, precisa-se discutir a aplicação de movimento para projeções focais. A pergunta é: há alguma evidência de que o movimento para posições focais seja ativado por checagem?

\footnotetext{
${ }^{20}$ Para mais debates sobre a questão, ver Kato (2004).

${ }^{21}$ Além da discussão para o português encontrada em Kato (2004), Rizzi (1997, p. 298) já propunha que o local de pouso de sintagmas-wh interrogativos movidos seja o Spec da projeção focal, considerando a impossibilidade de adjacência entre expressões não-wh focalizadas e sintagmas wh interrogativos. Nas palavras do autor, "(...) the possibility that immediately comes to mind is that the question operator sits in the Spec of Foc in main questions, hence focalized constituents and question operators compete for the same position and cannot co-ocur." Como se pode ver, a previsão de que sintagmas-wh interrogativos se movem para Foc já estava feita desde a organização Rizzi (1997), o que leva à noção de que o traço wh de palavras-wh é verificado conjuntamente a um traço de foco em Spec, FocP. Em Rizzi e Bocci (2017), encontramos a proposição de uma projeção IntP acima da projeção focal, que hospedaria palavras interrogativas, alternativamente à proposta de focalização apresentada em Rizzi (1997); isso se propõe em consonância com a proposta cartográfica, a qual prevê que cada traço precisa ser verificado por um núcleo distinto. Para nossa análise, entretanto, supor que o sintagmawh nas construções em análise se desloca para IntP após verificar seu traço de foco não responde ao fato de termos o stress focal ainda posto sobre o termo, a não ser que se postule que o wh, mesmo tendo seu traço de foco verificado, ainda conserva propriedades fonológicas focais ao se mover para IntP. Deixamos por hora esta questão em aberto e assumimos aqui Rizzi (1997), entendendo que em Spec, FocP o tgraço-wh seja valorado.
} 
Além disso, há ainda outro problema: se assumimos como em 2.3 que esse tipo de sentença infinitiva não projeta um sistema $\mathrm{CP}$, para onde estariam se movendo (se é que eles se movem) os sintagmas-Wh de $(5) b$ e (6)b, para que tenham seu traço-Wh checado, considerando que as referidas sentenças são claramente bem-formadas?

\subsection{Operações formais no programa de fases}

Chomsky (2000) inicia uma revisão da derivação de construções sintáticas numa perspectiva de Fases. A ideia geral é que a complexidade operacional do sistema é drasticamente reduzida se uma derivação ocorrer em pequenos estágios, com conteúdo proposicional, derivados a partir de subnumerações, que se constituem com base no primeiro arranjo de itens extraídos do Léxico. Entende-se que cada subnumeração contenha o suficiente para se constituir um objeto o mais próximo possível de uma proposição. Nessa perspectiva, consideram-se Fases fortes o $v^{*} \mathrm{P}$ e o $\mathrm{CP},{ }^{22}$ por conterem as condições necessárias para que sejam considerados como tal, a saber, o fato de conterem conteúdo proposicional.

Todo o complexo de operações formais aplicáveis no decurso da derivação de uma expressão é tido como se aplicando por fases, sendo limitada a atuação do sistema sobre elementos que estejam no interior de uma fase, quando ela se completa.

Em Chomsky (2001), operações formais de valoração de traços se dão por meio de um sistema sonda-alvo (probe-goal). Uma operação AGREE é disparada quando um objeto sintático é formado e porta traços não-interpretáveis $[u]$. Esse objeto se constitui numa Sonda que busca um Alvo compatível com ele em termos dos traços formais relevantes. É necessário que Sonda e Alvo estejam ativos para "disparar" Agree. Sonda e Alvo combinam quando os traços são valorados para o Alvo e não valorados para a Sonda.

Uma operação de valoração de traços formais pode, assim, acontecer à distância, com a permanência do alvo em sua posição de Base. Caso a Sonda contenha um conjunto de traços EPP, esses traços especiais ativam

\footnotetext{
${ }^{22}$ Sintagmas verbais com estrutura argumental completa $v^{*}$ Ps e CPs com indicadores de força são Fases fortes, mas não TPs ou configurações verbais "fracas" que não contêm argumento externo (como o que ocorre em construções passivas ou inacusativas). Assim, $v^{*} \mathrm{P}$ e CP são Fases fortes, e a subnumeração que constitui cada Fase contém exatamente um $v^{*}$ ou um C.
} 
o deslocamento do Alvo para uma configuração estrutural específica em relação a essa Sonda (posição de especificador). A existência de traços EPP associados a uma Sonda, segundo essa visão, está diretamente condicionada ao fato de tal Sonda possuir um conjunto completo de traços- $\varphi .{ }^{23}$ Também nos trabalhos referidos acima (i.e. CHOMSKY, 2000, 2001) já se instaura uma discussão acerca da natureza da relação entre $\mathrm{C}$ e $\mathrm{T}$, categorias funcionais correspondentes ao tipo oracional e ao tempo respectivamente. A ideia é que a existência de um T $\phi$-completo está diretamente relacionada ao fato de ser esse elemento diretamente selecionado por C. Isto é, um $\mathrm{T}$ selecionado por um $C$ possui um conjunto completo de traços- $\varphi$; um $\mathrm{T}$ que não seja selecionado por $\mathrm{C}$ será sempre defectivo.

A abordagem da relação C-T é, digamos, "energizada" em Chomsky (2005). Aí, corrobora-se a hipótese de que um T $\varphi$-completo é somente aquele que é selecionado por um $\mathrm{C}$ e chega-se além. Supõe-se que $C$ seja a categoria a que se associem traços- $\varphi$ e que $T$ apenas os herde de $\mathrm{C}$, quando de sua seleção por aquela categoria funcional. Se entre o complexo C-T e um DP ocorre Agree, este último pode permanecer in situ (com Agree à distância) tendo todos os seus traços formais valorados, ou pode ser deslocado para a posição de Spec-T, onde fica inativo, com todos os seus traços valorados e não pode mais ser alçado à posição de Spec-C (CHOMSKY, 2005, p. 9). Essa discussão é de importância seminal para as discussões que por ora se instauram. A relação C-T vai se mostrar determinante para o desenrolar da proposta deste trabalho. ${ }^{24}$ A seguir,

${ }^{23} \mathrm{Na}$ argumentação chomskiana, estas são as condições necessárias para "disparar" agree: que a sonda contenha um conjunto completo de traços phi. Por razões lógicas, estende-se o mesmo padrão de análise para uma operação de valoração de traços-wh ou traços focais, com uma sonda compatível em termos desses traços (nomeadamente, um núcleo $\mathrm{C}$, ou, como se verá mais adiante, o próprio item lexical wh, entendido como o operador focal).

${ }^{24}$ É importante observar aqui que a relação C-T tal como proposta em Chomsky e adotada neste trabalho não contém qualquer expressão de look ahead ou a postulação de uma derivação do tipo top-down. Entende-se que a derivação ocorra de baixo para cima (bottom-up), mas que a numeração, selecionada do léxico, contenha $\mathrm{C}$ e $\mathrm{T}$ respectivamente, sendo que $\mathrm{C}$ é o núcleo com os traços phi e irá, digamos, descarregar esses traços em T, no momento em que for concatenado no decurso da derivação. Além disso, uma proposta como essa não invalida a proposta cartográfica de Rizzi, uma vez que o próprio Rizzi em seu texto, (RIZZI, 1997, p. 28) discute a relação estreita entre o conteúdo proposicional de $\mathrm{C}$ e os traços de finitude em $\mathrm{T}$ (portanto a relação C-T), ao propor a projeção Fin como parte do sistema $\mathrm{CP}$. 
passo a discutir a questão do deslocamento para posições focais. Como se pretenderá mostrar, posições focais encontram-se em domínios com uma Sonda que apresenta um traço de Foco, que precisa ser compartilhado por alguma categoria substantiva presente na derivação.

\subsection{O que de fato está relacionado ao movimento para posições focais?}

Karimi (2003), em análise de dados do persa, afirma haver evidência suficiente para se considerar que movimento para posições focais seja ativado numa operação de valoração de um traço específico. Segundo a autora, essa língua exibe dois tipos de foco: um que aparece dentro do VP e que denota informação nova e outro que requer uma entonação (stress) bem acentuada e que expressa interpretação contrastiva.

Em persa, Whs que expressam contrastividade e que recebem uma acentuação mais proeminente movem-se opcionalmente; além disso, nessa língua, dois sintagmas-Wh podem sofrer movimento para uma posição de foco (contrastivo ou identificacional) na mesma sentença. Esse tipo de fenômeno, entretanto, sofre uma série de restrições que apontam para o movimento como resultado de checagem de um traço [-interpretável] de foco. Sejam os seguintes dados levantados pela autora:

$$
\begin{aligned}
& \text { (27) a. } \mathrm{KI}_{\mathrm{i}} \text { bâ } \mathrm{KI}_{\mathrm{j}} \text { pro fekr-mi-kon-I } \quad\left[\mathrm{CP} t_{\mathrm{i}} t_{\mathrm{j}}\right. \text { be-raghs-e] } \\
& \text { who with who thought-PROG-do-2SG subj-dance } 3 \mathrm{SG} \\
& \text { 'It is WHO with WHO you think you will dance?' } \\
& \text { É quem com quem você pensa que (você) irá dançar? }
\end{aligned}
$$$$
\text { b. ?? } \mathrm{KI}_{\mathrm{i}} \text { emruz bâ } \mathrm{KI}_{\mathrm{j}} \text { pro fekr-mi-kon-i [CP } t_{\mathrm{i}} t_{\mathrm{j}} \text { be-raghs-e] today }
$$$$
\text { (KARIMI, 2003,p. 298) }
$$

Uma das restrições, segundo a autora, é que em caso de movimento de múltiplos Whs focalizados, tem de haver entre eles adjacência (como em a); a presença de qualquer elemento entre eles (nesse caso o advérbio emruz 'hoje') resulta na má-formação da sentença (como se vê em b).

O caráter ruim de (27)b sugere que ambos os Whs deslocados devem estar ocupando dois especificadores do mesmo núcleo. A estrutura, portanto, seria algo como o que se vê em (28):

(28) $\left[\mathrm{FocP} \mathrm{XP}_{\mathrm{i}}\left[\mathrm{XP}_{\mathrm{k}}\left[\mathrm{Foc}^{\prime}\right.\right.\right.$ Foc $\left.\left.\left.\left[\mathrm{yp} \ldots t_{\mathrm{i}} \ldots t_{\mathrm{k}} \ldots\right]\right]\right]\right]$

O segundo argumento é constituído com base nos dados a seguir: 
(29) a. [faghat be Kimea $]_{\mathrm{i}}$ man $t_{\mathrm{i}}$ se ta KETAB dad-am

[ only to Kimea I three-part book gave-1sg

"It was only to Kimea that I gave three BOOKs." (I gave other people other things.)

Foi apenas a Kimea que eu dei três LIVROS

b. *se ta KETAB man faghat be KIMEA ti dad-am.

Significado pretendido: "It was three BOOKS that I gave only to KIMEA” (KARIMI, 2003, p. 299)

O contraste verificado em (29) a e b evidencia que a Condição do Elo Mínimo (MLC) deve ser obedecida quando dois elementos contendo o mesmo tipo de traço entram em competição por uma mesma posição. ${ }^{25}$ Observe-se que em (29)a temos o sintagma [faghat be Kimea] e o objeto direto acentuado KETAB ambos requerendo foco identificacional. Como se pode ver, o sintagma [faghat be Kimea] se moveu e o objeto permaneceu in situ. Quando, porém, em (29)b o objeto se move passando por sobre [faghat be Kimea], a sentença é ruim. Isso indica que movimento para posições focais está sujeito à MLC.

O mesmo tipo de efeito é verificado em construções com duplo-Wh; para que a sentença seja aceitável, um dos sintagmas deve permanecer in situ. É o que se vê nos dados em (30):

(30) a. $\mathrm{KI}_{\mathrm{i}}$ pro fekr mi-kon-i $\quad\left[_{\mathrm{CP}} t_{\mathrm{i}}\right.$ bâ $\mathrm{KI}$ be-raghs-e $]$ WHO _thought prog-do-2SG with WHO subj-dance-3SG 'WHO is it you think will dance with who?'

Quem é que você pensa (que) vai dançar com você?

b. *bâ KI $\mathrm{j}_{\mathrm{j}}$ pro fekr mi-kon-i $\left[\mathrm{CP} \mathrm{KI}_{\mathrm{i}} t_{\mathrm{j}}\right.$ be-raghs-e $]$

(KARIMI, 2003, p. 299)

${ }^{25} \mathrm{Ou}$ pode-se avaliar essa questão em termos minimalidade relativizada (RIZZI, 1990), a partir da ideia de que um núcleo relevante para uma operação de verificação não pode ser digamos "ignorado" em detrimento de outro depois dele com as mesmas propriedades. Em outras palavras, um B relevante em termos de traços que intervém entre A e C impede a relação entre A e C, ou, precisa ele ser o "preferido" na operação, não podendo ser "ignorado". 
Segundo Karimi, a sentença em (b) só é bem-formada se o Wh in situ não receber um acento focal, sendo nesses casos interpretado como um DP indefinido sem força quantificacional. Além disso, ainda segundo a autora, a ordem final de dois Whs deslocados também sofre um tipo de restrição, segundo a qual, elementos que podem ser movidos devem se mover para a posição de especificador mais próxima dentro de uma projeção com múltiplos especificadores (cf. RICHARDS 2002). ${ }^{26}$ Assim, em dados como os que se encontram a seguir, se o Wh mais baixo não for concatenado na posição de especificador mais baixa da projeção com múltiplos especificadores, a sentença é ruim, (31b). Se, entretanto, o fronteamento múltiplo de Whs obedece a essa restrição (como em (31a)), a sentença é bem-formada:

(31) a. $\mathrm{KI}_{\mathrm{i}}$ bâ KI $\mathrm{j}_{\mathrm{j}}$ pro fekr-mi-kon-i [CP $_{\mathrm{CP}} t_{\mathrm{i}} t_{\mathrm{j}}$ be-raghs-e]

WHO with WHO thought-prog-do-2SG subj-dance-3SG

b. *bâ $\mathrm{KI}_{\mathrm{j}} \mathrm{KI}_{\mathrm{i}}$ pro fekr-mi-kon-i $\left[_{\mathrm{CP}} t_{\mathrm{i}} t_{\mathrm{j}}\right.$ be-raghs-e]

(KARIMI, 2003, p. 299)

A conclusão é que, se o movimento para posições focais está sujeito a restrições que regem a aplicação de MOVE, então, esse tipo de movimento deve estar sendo ativado por checagem de traços não interpretáveis.

Seria possível pensar que de alguma forma os dados do português se comportassem de maneira semelhante, no que concerne a elementos Wh com um traço de foco? Argumento - em seção posterior - que em português Whs se movem abertamente para Foc após uma operação de valoração de um traço de foco.

\footnotetext{
${ }^{26}$ Pode parecer que uma proposta como a de Karimi (2003) mostre algum tipo de incompatibilidade com a proposta cartográfica quando a autora, citando Emonds (1976), menciona a existência de múltiplos especificadores. De fato, na teoria cartográfica de Rizzi (1997) e Beletti (2004) não se postula tal questão dadas as suas especificidades. Talvez esse seja um ponto fraco na argumentação, mas observe-se que é possível avaliar o que Karimi (2003) aponta como uma projeção com mais de um especificador de uma projeção focal como possibilidade de se estarem ativando, em vez disso, as duas projeções focais disponíveis no sistema CP para tratar dos efeitos de interveniência. Essa questão não é, entretanto, debatida pela autora, e fica aqui em aberto para análises futuras.
} 


\section{Iniciando a análise}

A boa-formação das sentenças $(5 b)$ e (6b) indica que todas as operações formais relevantes ocorreram ou essas derivações não seriam convergentes. Dessa avaliação, pode-se chegar a um dos dois vieses explicativos a seguir:

1) Em sentenças desse tipo o Wh encontra-se in situ e os traços relevantes são valorados por Agree à distância (cf. CHOMSKY, 2001); ou

2) $\mathrm{O}$ sintagma-Wh nesses casos não se encontra in situ, tendo sido afetado por algum tipo de movimento curto, que o deslocou para outra posição no interior da sentença.

A argumentação que se segue evidenciará que sintagmas-Wh nessas sentenças não podem estar em sua posição de base e que, portanto, apenas a segunda possibilidade é de fato viável.

\subsection{Movimento e atribuição de caso: o problema do sujeito de infinitivas}

Conforme argumentado em 3.3, em Chomsky (2005) intensificase uma discussão sobre a relação entre $\mathrm{C}$ e T. A ideia geral é que os traços$\varphi$ de $\mathrm{T}$ parecem ser herdados de $\mathrm{C}$. T não possui esses traços no léxico e passa a apresentá-los se e somente se for selecionado por C. Uma das evidências que se apresentam em favor dessa hipótese é o fato de não se poder mover o TP ou a impossibilidade dessa projeção aparecer isolada de C (CHOMSKY, 2005, p. 10). Assim, deduz-se, logicamente, que ao TP de uma sentença não-finita não se possam associar traços- $\varphi$ e que essas projeções não sejam, portanto, apropriadas para uma aplicação de Agree.

Tem-se que Sintagmas Nominais (NPs/DPs) precisam receber Caso no decurso da derivação. Considerando que nem na projeção temática (domínio do verbo leve) nem no domínio de T encontram-se os traços compatíveis para a atribuição de Nominativo, as sentenças em (32) e (33) são agramaticais.

(32) *A Maria chegar.

(33) *O João quer a Maria chegar. 
Em ambos os casos, a má-formação da sentença é explicada pelo fato de o DP "A Maria" não receber Caso Nominativo.

Observe-se, entretanto, que o dado em (34) contém uma construção bem-formada, em contraste com o que se vê em (33):

(34) O João viu a Maria chegar.

A questão é simples: na sentença em (34), está tudo certo com o DP “a Maria”.

Conforme mencionado em 2.1, assume-se tradicionalmente que sujeitos de sentenças infinitivas nessas circunstâncias encontram-se numa situação de atribuição excepcional de Caso (ECM), em que o DP recebe Caso do predicador da matriz. ${ }^{27}$ Se esse é o caso com as sentenças em questão, (a saber, (5a e b)), podemos assumir, de início, que o DP quem receba Caso nas mesmas condições.

Observe-se, entretanto, que - sem uma entonação focal específica para o sintagma-Wh - a sentença não é convergente:

35) a. *O João viu quem espirrar

b. *A Maria ouviu quem chorar.

Se, entretanto, o sintagma-Wh atinge o sistema CP da matriz, a sentença converge. O problema de (35) é prontamente resolvido se a derivação atinge o ponto de (5) e (6)c repetidos aqui como (36) a e b:

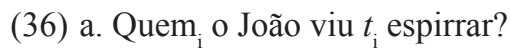

b. Quem ${ }_{\mathrm{i}}$ a Maria ouviu $t_{\mathrm{i}}$ chorar?

O fato é que os dados em (38) revelam algo interessante: se é possível um tipo de derivação em que o Wh atinge o CP da matriz, é preciso supor que de algum modo o Wh se desloca abertamente (de início) internamente à sentença em que é gerado, caso adotemos uma perspectiva de derivação por fases (como em/à la CHOMSKY, 2000, 2001, 2005).

Observe-se que, caso permaneça interno ao TP encaixado em sintaxe aberta, o sintagma-Wh jamais poderá ser alçado até o CP da

\footnotetext{
${ }^{27}$ Por enquanto ponho de lado uma análise mais arrojada como a de Hornstein, Martins e Nunes (2008), em função de uma simplicidade explicativa.
} 
matriz, considerando que, ao se completar a projeção máxima do verbo leve da oração principal, o domínio da fase (ou seja, o VP da matriz e tudo o que ele contém) é enviado para Spell-Out e a computação não tem mais acesso a nada nesse domínio.

Pode-se optar por uma alternativa de análise segundo a qual todo o procedimento de atribuição de Caso se dê excepcionalmente e que o traço de Foco funcione como um traço de borda, posicionando o Wh na periferia da primeira fase forte $\mathrm{V} * \mathrm{P}$, de maneira a livrá-lo do efeito de congelamento (PIC - condição de impenetrabilidade da fase) e de tal modo que ele possa ser acessado daí por elementos na próxima fase. A derivação, nesses termos, se daria da maneira que segue:

1) O DP quem recebe Caso excepcional;

2) Um traço de borda (nesse caso o traço de foco) eleva o sintagmaWh para a periferia da Fase forte $v^{*} \mathrm{P}$;

Quando C é concatenado, ocorre toda a relação do sistema C-T e um traço Wh em C, conjuntamente com um traço de borda (cf. CHOMSKY, 2005, p. 15), atrai o sintagma-Wh para a posição mais alta, resultando no que se vê em (36).

Apesar de se poder com essa análise dar conta de alguns fatos concernentes à derivação desse tipo de estrutura, ainda falta explicar dados como (37) e a agramaticalidade de dados como (38).

Está claro que, com uma entonação focal (seja ela ascendente ou descendente) sobre o sintagma-Wh, as sentenças são perfeitamente viáveis, como o que se vê em (5) e (6) b, repetidos a seguir como (37) a e b; sem essa entonação, as sentenças não convergem (38) a e b.

(37) a. O João viu QUEM $\uparrow \downarrow$ espirrar?

b. A Maria ouviu QUEM $\uparrow \downarrow$ chorar?

(38) a. *O João viu quem espirrar.

b. *A Maria ouviu quem chorar.

A questão que se põe aqui é: como a derivação de (37) ocorre? Avaliemos essa questão. 


\subsection{Aparente Wh in-Situ e a periferia interna da sentença}

Já sabemos que, em sentenças infinitivas encaixadas como as que se avaliam aqui, Whs têm de estar se movendo abertamente, ou não seria possível a derivação de (36). Também já ficou claro que se pode falar em um traço [-interpretável] de foco, que interage para a existência de movimento para posições focais. Agora, restam duas questões basilares: 1) Em (37), como se dá a valoração de um traço de foco (e sincreticamente de um traço [+wh]) com o sintagma-Wh nessa posição (aparentemente in situ), se já se sabe que não há um CP dominando a construção?; 2) Se ocorre de fato movimento aberto do Wh para um posição focal em (37), que posição focal seria essa?

Belletti (2004) argumenta que há razões empíricas para considerar a existência de uma periferia interna ao IP com características semelhantes à que se propõe para o CP. Em particular, o fato de que há uma posição focal interna, que intercala posições de tópico. Para ela, entonações distintas, bem como interpretações diferentes são associadas a essas posições, em oposição às posições paralelas na periferia da sentença (p. 17). Essas diferenças entoacionais e interpretativas seriam devidas a propriedades da configuração em si.

A área interna ao IP teria a seguinte configuração:

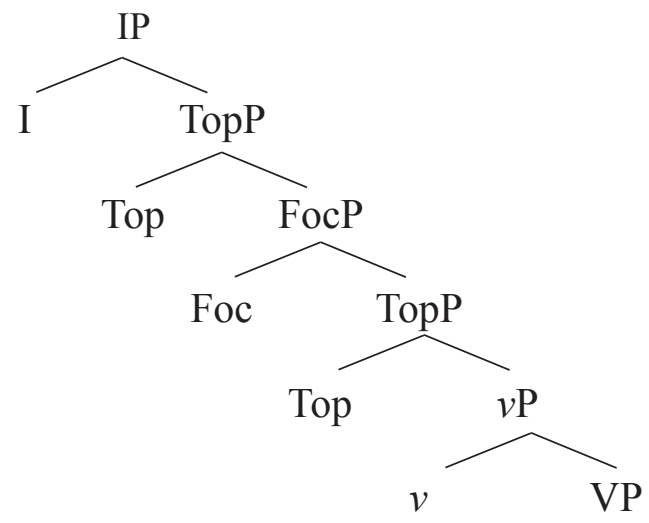

A hipótese básica de Belletti (2004) é que a posição focal na periferia esquerda da sentença está relacionada à interpretação de foco contrastivo, enquanto a posição interna ao IP detém a interpretação informacional. 
Considerando que a hipótese da existência de uma periferia do IP esteja correta, passo a argumentar, seguindo Kato (2004), que Whs aparentemente in situ em português do Brasil são na verdade casos de deslocamento curto para a posição de foco interna ao IP. ${ }^{28}$ Essa hipótese consegue prover uma explicação adequada para o paradigma em (5) e (6).

Conforme observado anteriormente, a derivação de (5) e (6)c só é possível, se admitirmos movimento aberto do sintagma-Wh para o especificador do verbo leve na oração mais alta (em virtude de um traço de borda). Movendo-se em sintaxe aberta para o Spec- $v \mathrm{P}$, o Wh se encontra na periferia da fase e pode ser acessado de lá pela sonda da matriz (o núcleo C) e satisfazer as propriedades desse núcleo funcional. ${ }^{29}$ Pensemos na estrutura das sentenças infinitivas em discussão aqui (dados como o de (37)). Admitiu-se em 2.3 que o que de fato encontramos em sentenças como (5) e (6) b são TPs encaixados. Assim, supõe-se que o sintagma-Wh mova-se abertamente para Spec- $v \mathrm{P}$, como argumentado anteriormente, e esteja então visível para a sonda $\mathrm{Foc}^{0}$ na periferia do verbo leve da oração matriz. Nesse ponto, ocorre o procedimento de Agree, que valora o traço Wh e a atração do Wh para a posição do especificador de FocP, ativado pelo traço de foco, que, segundo já se assumiu, funciona como um traço de borda. A derivação se daria da maneira como se vê a seguir:

$$
\begin{aligned}
& \text { (40) }\left[_ { \mathrm { CP } } \left[_ { \mathrm { TP } } \text { O João } { } _ { \mathrm { k } } \left[_ { \mathrm { T } } \text { viu } _ { \mathrm { j } } \left[_ { \mathrm { FocP } } \mathrm { QUEM } _ { \mathrm { i } } \left[_ { \mathrm { Foc } } { } ^ { 0 } \left[_ { \mathrm { TopP } } \left[_ { v \mathbf { P } } \text { QUEM } _ { \mathrm { i } } \left[_ { v \mathbf { P } } t _ { \mathrm { k } } \left[\left[_{\mathrm{VP}} t_{\mathrm{j}}\right.\right.\right.\right.\right.\right.\right.\right.\right.\right. \\
& \left.\left.\left.\left.\left.\left.\left.\left.\left[_{\mathrm{TP}} \text { QUEM }_{\mathrm{i}}\left[_{\mathrm{VP}} \text { espirrar }\right]\right]\right]\right]\right]\right]\right]\right]\right]\right] ?
\end{aligned}
$$

Uma pergunta natural a se fazer nesse ponto seria: por que não dizer que a posição focal contra a qual o Wh verifica seu traço de foco encontra-se na periferia projetada no TP encaixado?

\footnotetext{
${ }^{28}$ Para uma visão diferente sobre Whs aparentemente in situ, movimento e WhAgreement, cf. Reintges, LeSourd e Chung (2006).

${ }^{29}$ Entende-se que esse movimento seja motivado pela existência de um traço de foco que acaba sendo responsável pelo posicionamento do sintagma-Wh na periferia da fase, o que se constituiria numa espécie de traço de borda (cf. CHOMSKY, 2005; BǑSKOVIČ, 2008b). A periferia da Fase, nesse caso, constitui coincidentemente o ponto em que se dá a checagem do traço de Caso. Também se pode admitir, adotando argumentação mais recente da teoria que o traço de Caso seja atribuído por Agree à distância e que o traço de Foco, aqui entendido como um traço de borda, desloca o sintagma para a periferia da Fase vP.
} 
A resposta é simples: TPs infinitivos não parecem dispor de uma periferia interna projetada, a julgar pelo que se vê nos dados em (41) a seguir:

(41) a. *O JOÃO chegar é importante.

b. *A MARIA comprar um carro surpreendeu a todos.

c. *QUEM chegar incomodou a todos.

Se considerássemos a existência da projeção de uma periferia interna ao TP nesses casos, o sujeito em questão poderia ser focalizado nessa posição específica e as sentenças seriam convergentes, contrariamente aos fatos. Nos contextos em que a infinitiva não é selecionada, o foco tem de recair sobre todo o TP:

(42) a. O JOÃO CHEGAR é importante.

b. A MARIA COMPRAR UM CARRO surpreendeu a todos.

Apenas (42)a é a resposta apropriada para a pergunta: o que é importante?, não (41)a; assim como somente (42)b responde adequadamente à pergunta: o que surpreendeu a todos? E não (41)b.

Seja (37) repetido a seguir como (43):

(43) a. O João viu QUEM $\uparrow \downarrow$ espirrar?

b. A Maria ouviu QUEM $\uparrow \downarrow$ chorar?

Em (43), o sujeito-Wh pode ser focalizado, ao passo que em (42) - sentenças infinitivas não encaixadas - só é possível focalizar todo o TP. Conclui-se que, em casos como (43 a e b), o sujeito-Wh precisa estar sendo focalizado no TP matriz e não no encaixado, já que se supõe não haver uma posição focal no TP infinitivo.

Conforme se argumentou anteriormente, muitas das propriedades de $\mathrm{T}$ são derivadas da relação dessa categoria com $\mathrm{C}$, como a presença de traços- $\varphi$ ou de traços EPP. É provável que a capacidade do vP de projetar uma periferia esteja também diretamente condicionada ao fato de ser encabeçado por um $\mathrm{T}$ que seja necessariamente selecionado por C. TPs infinitivos (não selecionados por $\mathrm{C}$, portanto) não conteriam um $v$ P capaz de projetar uma periferia. 
Resta avaliar, então, o que causa a agramaticalidade em sentenças como (44) a e b.

(44) a. *O João viu quem chegar

b. *A Maria ouviu quem chorar

Considere-se que, se o Wh (quem) em questão não atingir abertamente o especificador do verbo leve da matriz, o domínio dessa fase sofrerá Spell-Out, assim que ela se completar, e nada mais poderá ser acessado em seu interior para quaisquer operações posteriores do sistema; isso constitui o que se chama PIC (Condição de Impenetrabilidade da Fase).

Suponhamos, assumindo Boškovič (2008b), ${ }^{30}$ que a PIC seja algo de natureza estritamente fonológica ${ }^{31}$ e que certo elemento (dotado de uma espécie de traço de borda $-u \mathrm{~K}$ ) precisa ser movido para a periferia de uma dada fase, para atender a exigências da fonologia. Nessa posição, esse elemento acha-se disponível para ser acessado pela derivação em fases posteriores, podendo ser pronunciado em outra posição na sentença.

Imaginemos, como já se argumentou, que seja exatamente o traço de Foco o responsável pelo movimento aberto do sintagma-Wh para o domínio do verbo leve da matriz. Um sintagma-Wh nesse tipo de construção que não adentre a Numeração portando um traço de Foco não é movido e, nesse caso, preso dentro da fase mais baixa, contém um traço-Wh não valorado, o que explica a má-formação das sentenças.

Se a ausência do traço de Foco resulta no não-alçamento do sintagma-Wh em sintaxe aberta para o domínio do verbo leve da matriz, então, esse elemento não acessa a projeção Focal no domínio do TP mais alto, nem tampouco conseguirá atingir o $\mathrm{CP}$ da matriz, e permanecerá

\footnotetext{
${ }^{30}$ Ponho aqui de lado especificidades da proposta de Boškovič (2008b), que representa, na verdade uma revisão do sistema Agree de Chomsky. Segundo essa nova ideia, o item lexical dotado de um traço K (uK) é movido para a periferia da fase e, na posição de especificador de uma projeção funcional, torna-se a sonda, busca o alvo e dispara Agree. Trata-se, portanto, de uma inversão de EPP. É provável que uma análise nesses termos seja bastante interessante. Todavia, como disse, ponho de lado essas questões específicas e assumo a ideia de que a PIC tenha mesmo natureza absolutamente fonológica.

${ }^{31}$ Segundo essa visão, por razões interpretativas, sucessivas fases podem ser violadas pelo sistema computacional, mas em termos fonológicos, nada pode ser retirado do interior de uma fase quando ela se completa e seu domínio é enviado para Spell-Out.
} 
com um traço Wh não valorado; ${ }^{32,33}$ dessa forma, a sentença não converge em LF.

Assim, a conclusão a que se chega é que o que se tem em sentenças como (37) é um caso de Wh aparentemente in situ. Sintagmas-Wh nessas sentenças encontram-se de fato fora da sua posição de base, movidos por um traço de borda (nesses casos um traço de Foco) (o que tem a ver com as propriedades do sujeito de uma infinitiva que complementa um verbo de percepção) e pela necessidade de valorar um traço de Wh, numa projeção focal no domínio do TP mais alto.

Se a hipótese de que a focalização de sujeitos de infinitivas que complementam verbos como ver e ouvir é um recurso para explicar sentenças com wh estiver correta, ela faz uma previsão de que seja possível focalizar outros DPs nas mesmas condições, a saber, sujeitos

${ }^{32}$ Considero aqui que o CP da matriz contenha um traço-Wh forte a julgar pela existência de sentenças como (i) a e b, em que o Wh se encontra na periferia da matriz:

(i) a. Quem o João viu $t_{\mathrm{i}}$ chorar?

b. Quem ${ }_{\mathrm{i}}$ a Maria viu $t_{\mathrm{i}}$ espirrar?

Se assumirmos a visão de que o traço formal é algo que se encontra no item lexical e não no núcleo funcional (cf. SIMPSON, 2000; BOŠKOVIČ, 2008a, 2008b) talvez possamos dar a esse tipo de sentença um tratamento interessante.

Um traço de borda $(u \mathrm{~K})$ no sintagma-Wh seria responsável por posicioná-lo no especificador de um núcleo na borda de uma fase, para que ele, como sonda, busque um núcleo compatível em termos de traços, libere Agree e resolva seus requerimentos formais.

Entretanto, se assumimos essa visão e admitimos que em (i) a e b há projeções focais antes do CP da matriz nas quais o traço de foco do sintagma-Wh poderia ter sido verificado, encontramos um problema para essa análise. Se assumirmos com Chomsky (1995) o sistema Agree tradicional em que o núcleo funcional é o portador do traçoWh que deve ser eliminado e que um mesmo sintagma-Wh pode participar de várias operações de checagem numa mesma derivação, resolvemos esse dilema. Como se trata de uma questão controversa, deixo-a aqui em aberto para investigações futuras.

${ }^{33}$ Outra questão relevante é a seguinte: se não consideramos que esses dados tenham natureza interrogativa, temos de levar em conta o fato de que o $\mathrm{C}^{0}$ da matriz não contém um traço-Wh forte; sua força é declarativa. Mesmo que todo o procedimento descrito para os dados com foco no Wh se processe, o sintagma-Wh termina a derivação portando um traço não verificado. $\mathrm{O}$ fato é que dados desse tipo podem representar uma evidência em favor de hipóteses como as de Boškovič (2008b) e Simpson (2000), segundo as quais é o item lexical em si (o sintagma-Wh), em vez do núcleo $\mathrm{C}^{0}$, quem contém um traço que precisa ser verificado. 
de sentenças infinitivas complementos de verbos de percepção, já que as operações previstas num e noutro caso são basicamente similares. ${ }^{34}$ Observe-se que isso é de fato possível, em contextos discursivos específicos, em que as condições de focalização se aplicam:

(45) Cada um dos rapazes viu uma menina chorar; o João viu QUEM chorar, a Maria ou a Ana?

(46) O João viu a MARIA chorar.

Um problema para esta análise vem com dados como o que se apresenta em (47) a seguir.

(47) O João viu a Maria beijar QUEM?

Se a hipótese de que a sentença infinitiva não projeta uma periferia estiver de fato correta, não deveria ser possível derivar Wh focalizado nas condições em que está, conforme o que propõe Kato (2004). Essa questão, dada a assimetria que se verifica entre posições se sujeito e complemento para a aplicação de operações sintáticas, fica em aberto para investigações posteriores.

\section{Considerações finais}

Procurei mostrar neste trabalho que sentenças com Wh aparentemente in situ em perguntas encaixadas infinitivas do português representam na verdade casos de Whs movidos para uma posição focal interna ao TP. Tentei mostrar que o movimento para foco deve ser entendido - num viés Minimalista - como um procedimento de checagem de traços e que só uma opção de movimento aberto para Foco em português pode explicar os fatos posto pelos dados em (5) e (6)c.

Busquei evidenciar que uma interação entre as propriedades de infinitivas que complementam verbos de percepção e a questão do deslocamento-Wh e de procedimentos de focalização são a chave para tentar explicar o paradigma posto em (5) e (6).

\footnotetext{
${ }^{34}$ Ressalte-se aqui que isso pode ser suposto desde que o DP, qualquer que seja ele, adentre a derivação portando um traço de foco, assim como se supõe que ocorra com o sintagma-wh.
} 
Em minha argumentação, também busquei mostrar que, em português, o traço-Wh de um sintagma dessa natureza é checado sincreticamente junto com um traço de Foco numa projeção focal, considerando o fato de que as sentenças postas em questão aqui só convergem se o Wh recebe um Stress focal proeminente.

Uma análise foi proposta para interrogativas infinitivas encaixadas com base em uma tipologia verbal. Argumentou-se que em sentenças infinitivas encaixadas que contêm um verbo inacusativo o traço de Foco do sintagma-Wh é checado contra a projeção focal que domina o verbo leve da matriz e que, em casos de verbos inergativos ou transitivos comuns, o traço de Foco (e conjuntamente o traço-Wh) é checado contra o núcleo $\mathrm{Foc}^{0}$ projetado no domínio do TP encaixado.

\section{Agradecimentos}

Agradeço a Esmeralda Negrão pela discussão desse trabalho no XXXI Encontro Nacional da ANPOLL, ocorrido em Campinas em 2016. Suas ideias foram incrivelmente valiosas. Eu assumo, é claro, toda a responsabilidade pelo que está dito aqui.

\section{Referências}

BELLETTI, A. Aspects of the low IP area. In: RIZZI, L. (Ed.). The structure of CP and IP: the cartography of syntactic structures. New York: Oxford University Press, 2004.

BIANCHI, V. Consequences of antisymmetry: Headed Relative Clauses. Berlin: Mouton de Gruyter, 1999. Doi: https://doi. org/10.1515/9783110803372

BORER, H. I-subjects. Linguistic Inquiry, MIT Press, v. 17, p. 375-416, 1986.

BOŠKOVIČ, Z. Move vs Agree. Handout apresentado no Curso de Sintaxe Minimalista. São Paulo: Universidade de São Paulo, 2008a.

BOŠKOVIČ, Z. Driving Force and Freezing Effects. Handout apresentado no Curso de Sintaxe Minimalista. São Paulo: Universidade de São Paulo, 2008b. 
CHENG, L. L. S. On the Typology of WH-Questions. 1991. Dissertation (Doctorate) - MIT, 1991.

CHOMSKY, N. Barriers. Cambridge, Mass.: MIT Press, 1986.

CHOMSKY, N. The Minimalist Program. Cambridge, Mass: MIT Press, 1995.

CHOMSKY, N. Minimalist Inquiries: The Framework. In: MARTIN, Roger; MICHAELS, David; URIAGEREKA, Juan (Ed.). Step by step: Essays on Minimalist Syntax in honor of Howard Lasnik. Cambridge, Mass.: MIT Press, 2000.

CHOMSKY, N. Derivation by Phase. In: KENSTOWICZ, M. (Org.). Ken Hale: A Life in Language. Cambridge, Mass: MIT Press, 2001.

CHOMSKY, N. On Phases. Ms. Cambridge, Mass.: MIT Press, 2005.

EMONDS, J. A Transformational Approach to English Syntax. New York: Academic Press, 1976.

FELSER, C. Verbal Complement Clauses - A Minimalist Study of Direct Perception Constructions. Amsterdam; Philadelphia: John Benjamins Publishing Company, 1999. Doi: https://doi.org/10.1075/la.25

GEORGE, L. Analogical Generalization in Natural Language Syntax. 1980. Dissertation (Doctorate) - MIT, 1980.

GUESSER, S.; QUAREZEMIN, S. Focalização, cartografia e sentenças clivadas do português brasileiro. Revista Linguística, UFRJ, Rio de Janeiro, v. 9, p. 30-63, 2013.

HORNSTEIN, N.; MARTINS, A. M.; NUNES, J. Perception and Causative Structures in English and European Portuguese: $\varphi$-feature Agreement and the Distribution of Bare and Prepositional Infinitives. Syntax, Wiley Online Library, v. 11, n. 2, p. 198-222, 2008. Doi: https:// doi.org/10.1111/j.1467-9612.2008.00105.x

KARIMI, S. Focus movement and the nature of uninterpretable features. In: CARNIE, A.; HARLEY, H.; WILLIE, M. (Ed.). Formal approaches to function in Grammar. Amsterdam; Philadelphia: John Benjamins Publishing Company, 2003. Doi: https://doi.org/10.1075/la.62.21kar 
KATO, M. A. Two types of wh-in-situ in Brazilian Portuguese. Georgetown Round-Table in Languages and Linguistics. Washington, DC, 2004.

KAYNE, R. Connectedness and Binary Branching. Dodrecht: Foris, 1984. Doi: https://doi.org/10.1515/9783111682228

KOSTER, J.; MAY, R. On the constituency of infinitives. Language, Washington, v. 58, p. 116-143, 1982. Doi: https://doi.org/10.2307/413533

LOBATO, L. M. P. Sintaxe gerativa do Português. Da Teoria padrão à teoria da regência e ligação. Belo Horizonte: Vigília, 1986.

MEDEIROS JUNIOR, P. Sobre Sintagmas-Qu e Relativas Livres no Português. 2005. Dissertação (Mestrado) - Universidade de Brasília UnB, Brasília, DF, 2005.

MIOTO, C. As interrogativas no português brasileiro e o critério WH. Letras de Hoje, Porto Alegre, v. 29, n. 2, p. 19-33, 1994.

POLLOCK. J.-Y. Verb movement, UG and the structure of IP. Linguistic Inquiry, MIT Press, v. 20, p. 365-424, 1989.

QUAREZEMIN, S. Estratégias de focalização no português brasileiro: uma abordagem cartográfica. 2009. Tese (Doutorado em Linguística) UFSC, Florianópolis, 2009.

RADFORD, A. Syntactic Theory and the Structure of English: a Minimalist Approach. Cambridge: Cambridge University Press, 1997. Doi: https://doi.org/10.1017/CBO9781139166706

REINTGES, C. H.; LeSOURD, P.; CHUNG, S. Movement, WhAgreement, and Apparent Wh-in-situ. In: CHENG, L.; CORVER, N. (Ed.). Wh-Movement-Moving on . Cambridge. Mass: MIT Press, 2006.

REULAND, E. On the Governing Properties of Infinitival Markers. In: FRETHEIM, T.; HELLAN, L. (Ed.). Papers form the Sixth Scandinavian Conference of Linguistics. Trondheim: Tapir, 1981.

RICHARDS, N. Movement in Language. Oxford: Oxford University Press, 2002.

RIZZI, L. Residual Verb Second and the Wh Criterion. Technical Reports in Formal and Computational Linguistics 2. Geneva: University of Geneva, 1991. 
RIZZI, L. The Fine Structure of Left Periphery. In: HAEGMAN, L. (Org.). Ellements of Grammar. Dodrecht: Kluwer, 1997. p. 281-337. Doi: https://doi.org/10.1007/978-94-011-5420-8_7

RIZZI, L.; BOCCI, G. The left periphery of the clause - primarily illustrated for Italian. In: EVERAERT, M.; VAN RIEMSDIJK, H. C (Ed.). Blackwell Companion to Syntax, II edition. New Jersey: Wiley-Blackwell, 2017. Doi: https://doi.org/10.1002/9781118358733. wbsyncom 104

RIZZI, L. Relativized Minimality. Cambridge: MIT Press. 1990

RODRIGUES, P. A. Les Compléments Infinitifs et Gérondifs des Verbes de Perception em Portugais Brésilien. 2006. Tese (Doutorado)Universidade de Quebec, Montreal, 2006.

ROUVERET, A.; VERGNAUD, J. R. Specifying Reference to the Subject: French Causatives and Conditions on Representations. Linguistic Inquiry, MIT Press, v. 11, p. 97-202, 1980.

SIMPSON, A. Wh-Movement and the Theory of Feature Checking. Amsterdam: John Benjamins B. V, 2000.

WATANABE, A. The pied-piper feature. In: CHENG, L.; CORVER, N. (Ed.). Wh-Movement-Moving on. Cambridge. Mass: MIT Press, 2006. 